\title{
Dental caries and social factors: impact on quality of life in Brazilian children
}

\section{Milene Torres MARTINS Fernanda SARDENBERG Míriam Pimenta VALE Saul Martins PAIVA Isabela Almeida PORDEUS}

Universidade Federal de Minas Gerais - UFMG, Faculdade de Odontologia, Departamento de Odontopediatria e Ortodontia, Belo Horizonte, MG, Brazil.
Declaration of Interests: The authors certify that they have no commercial or associative interest that represents a conflict of interest in connection with the manuscript.

Corresponding Author:

Milene Torres Martins

E-mail:mileneelaura@yahoo.com.br

DOI: 10.1590/1807-3107BOR-2015.vol29.0133

Submitted: Oct 13, 2014

Accepted for publication: Jun 09, 2015

Last revision: Aug 28, 2015
Abstract: The objective of this study was to evaluate the impact of dental caries and social determinants in the Oral Health Related Quality of Life (OHRQoL) of children in Belo Horizonte, Brazil. This is a population-based cross-sectional study with a representative sample of 1,204 children aged 8 to 10 years randomly selected from 19 public and private schools. The children were clinically examined at school by two trained and calibrated examiners (Kappa $=0.78-1.00)$. The Decayed, Missing and Filled Teeth Index (DMF-T and dmf- $t$ ) was used for the diagnosis of dental caries. The social factors were determined by parents'/caregivers' schooling, household income, number of people in the household, type of school, and by the Social Vulnerability Index. The Brazilian version of the Child Perceptions Questionnaire for ages 8 to 10 years was used to assess the impact on quality of life. A total of 278 $(23.1 \%)$ out of 1,204 children had at least one cavitated carious lesion and $47.0 \%$ presented a negative impact on OHRQoL. In the final multivariate Poisson's regression model, household income and presence of untreated dental caries were statistically associated with a negative impact on OHRQoL $(p<0.001)$. Children with dental caries and from low-income families had a higher negative impact on OHRQoL.

Keywords: Quality of Life; Dental Caries; Child.

\section{Introduction}

Dental caries is a prevalent disease among children ${ }^{1}$ and can influence their quality of life in activities such as eating, sleeping, talking and enjoying the general health..$^{2,3}$ In addition, dental caries affects young children's growth and well-being., ${ }^{4,5}$

There is growing interest in assessing the impact of oral conditions on quality of life. ${ }^{6}$ It is suggested that the measurement of Oral Health-Related Quality of Life (OHRQoL) should be an essential component of oral health surveys. ${ }^{7}$ However, most studies addressing the pediatric population involve preschool children ${ }^{3,8,9,10}$ or those whose permanent dentition is fully established. ${ }^{11,12,13}$ Few studies ${ }^{14,15,16}$ have been conducted with children in the mixed dentition stage. Nonetheless, it is essential to evaluate the impact of dental caries on these children's quality of life, taking into account their own perceptions. Given that, at the age of eight years, children already consider health to be a set of somatic and emotional symptoms, they are able to report all aspects of their health, using the same criterion of attractive as with adults. ${ }^{17}$ In a systematic literature 
review on the association between social factors and OHRQoL, poorly educated and low-income women were associated with better perception of negative impacts on OHRQoL. ${ }^{18}$ Furthermore, elderly people reported less of an impact than did their younger counterparts. ${ }^{18}$ Notwithstanding, the association between social factors and the impact of dental caries on OHRQoL in younger people or children is not well established, because a significant association between age and a negative impact could only be found in the bivariate analyses of some studies. ${ }^{18}$ In other studies using multivariate-adjusted models, social factors such as low mother's education and low household income were statistically associated with a higher negative impact on Child Oral Health-Related Quality of Life (COHRQoL)., ${ }^{9,1920}$ Moreover, high family income can be a protective factor for COHRQoL. ${ }^{20}$

The objective of this study was to evaluate the negative impact of dental caries and social determinants on the quality of life of 8-10-year-olds in Belo Horizonte, Brazil.

\section{Methodology}

\section{Study design}

A cross-sectional survey was carried out with a representative sample $(1,204$ male and female children aged 8 to 10 years attending public and private elementary schools) in the city of Belo Horizonte, Brazil, which is divided into nine regional areas of local administration. A multistage sampling technique was used to select the children. The sample size was calculated using an a-value of 0.05 , a detectable error of $3 \%$, and an expected prevalence of $62.3 \%$, totaling 1,002 children. The prevalence used for sample size calculation was that of the pilot study, due to the paucity of prevalence studies for this age group. The sample size was multiplied by 1.2 due to the clustering effect ${ }^{21}$ and an additional $20 \%$ was added to compensate for possible losses, adding up to 1,442 children (a total of 1,436 informed consent forms were obtained). To ensure representativeness, the sample was stratified according to administrative district and type of school. The percentage distribution of 8-to-10-year-olds in each administrative district was calculated based on the information provided by the local Board of
Education. The distribution of participants was then determined by the proportion of this population in the respective school systems using data from the samples. The first stage consisted of randomly selected public and private elementary schools in each administrative district of Belo Horizonte. In the second stage, classes were randomly chosen from the selected schools.

\section{Data collection}

Two calibrated examiners used the Decayed, Missing and Filled Teeth Index (DMFT/dmft) ${ }^{22}$ for the diagnosis of dental caries. Dental caries was present if children had one or more teeth with untreated carious lesions. The Dental Aesthetic Index (DAI) ${ }^{23}$ criteria were used to assess malocclusion (confounding variable), which was dichotomized as either absent malocclusion (DAI $\leq 25)$ or present malocclusion (DAI > 25). Dental examinations were carried out at the schools during daytime hours. The examiners used appropriate sterilized equipment to avoid crossinfection among the children.

During the calibration process, the examiners evaluated 70 children $(5.8 \%$ of the sample and not part of the study population) from a convenience sample to assess inter-rater agreement $($ Kappa $=0.78-1.00)$ and re-examined these children after two weeks to assess intra-rater agreement (Kappa $=0.93-1.00)$.

The parents/caregivers provided information on their economic status when they signed the free and informed consent form. The socioeconomic background was determined using parents'/caregivers' schooling, household income, number of people in the household $(\leq 4$ or $>4)$, type of school (private or public), and the Social Vulnerability Index. The Social Vulnerability Index is a local measure based on neighborhood infrastructure and access to work, income, sanitation services, healthcare services, education, legal assistance, and public transportation, ${ }^{24}$ and was determined from children's addresses. The index categorizes children's addresses into five classes (class I to class V), with class I indicating the highest degree of social vulnerability and class $\mathrm{V}$, the lowest one. The five classes were dichotomized into classes I and II for high vulnerability and III, IV and V for low vulnerability. 
In the assessment of schooling, parents or caregivers who had completed eight years of formal education, which in Brazil corresponds to elementary school, were compared with those who had not. Household income was measured in terms of the Brazilian minimum wage (up to $2 \mathrm{BMW}$ or more than $2 \mathrm{BMW}$ ). In Brazil, children from a higher socioeconomic status usually go to private schools whereas those from a lower socioeconomic status attend public schools.

The Brazilian version of the Child Perceptions Questionnaire for ages 8 to 10 years was used to assess the impact on quality of life. An OHRQoL instrument was designed exclusively for this age group. This instrument has been proven valid and reliable for use in Brazilian children. ${ }^{25}$ This instrument consists of 25 items distributed into four subscales: oral symptoms (5 items), functional limitations (5 items), emotional well-being ( 5 items), and social well-being (10 items). The items address the frequency of events in the four previous weeks. The following five-point rating scale was used: never $=0$; once $/$ twice $=1$; sometimes $=2$; often $=3$ and every day/almost every day $=4 . \mathrm{CPQ}_{8-10}$ scores were calculated by adding the scores of all items, yielding a total score from 0 (no impact of oral condition on OHRQoL) to 100 (maximum impact of oral condition on OHRQoL). For the statistical analysis, the impact on OHRQoL was classified as either low $\left(\mathrm{CPQ}_{8-10} \leq 10\right)$ or high $\left(\mathrm{CPQ}_{8-10}>10\right)$ based on the median value of $\mathrm{CPQ}_{8-10}$ total score. Dental caries was considered present if the children had at least one cavitated carious lesion.

\section{Data analysis}

The Statistical Package for Social Sciences, version 17.0 (SPSS Inc., Chicago, USA), was used for the statistical analysis. The Kolmogorov-Smirnov test could not confirm the normality of the sample. The Poisson regression model with robust variance was used for the univariate and multivariate analyses.

\section{Ethical Approvals}

The study was approved by the Human Research Ethics Committee of the Universidade Federal de Minas Gerais - UFMG (protocol no. 04.65.0.203.000-09). Parents/guardians and children read and signed an informed consent form prior to their participation in the study.

\section{Results}

One thousand two hundred and four $(1,204)$ children were examined (boys accounted for $44.7 \%$ and girls for 55.3\%), among whom 8-, 9- and 10-year-olds represented $28.2 \%, 35.5 \%$, and $36.3 \%$ of the sample, respectively. The response rate was $83.3 \%$.

The majority of the children lived in households with up to four persons (60.9\%), their parents or caregivers had eight years or more of schooling $(70.0 \%)$ and a family income equal to 2 or more than 2 BMW (50.8\%). Of the total sample (1,204), 76.5\% were attending public schools and $63.0 \%$ lived in areas of low social vulnerability.

A total of $278(23.1 \%)$ children had at least one cavitated carious lesion; 388 (32.2\%) had malocclusion; and 566 (47.0\%) presented high impact on OHRQoL.

In the bivariate analysis, a high impact on OHRQoL was significantly associated with the presence of cavitated carious lesions ( $p<0.001)$, publicly schooled children $(p<0.001)$, parents with fewer than eight years of schooling, children from families whose household income was less than 2 BMW ( $p<0.001)$, and children who lived in households with four or more people $(p=0.011)$ (Table 1$)$.

In the univariate Poisson regression model, gender, the social vulnerability index, and the number of residents in the household were not statistically associated with the impact on OHRQoL ( $p>0.05$ ). In the final multivariate Poisson regression model, only household income and presence of untreated dental caries were statistically associated with a high impact on OHRQoL. Children with untreated dental caries were 1.41 times (95\%CI:1.25 to 1.59; $\mathrm{p}<0.001)$ more likely to experience a high impact on OHRQoL than those without cavitated carious lesions. Children whose household income was less than 2 BMW were 1.31 times $95 \%$ CI:1.15 to $1.51 ; \mathrm{p}<0.001$ ) more likely to experience a high impact on OHRQoL than those whose household income was higher than 2 BMW (Table 2).

Malocclusion was the only variable kept in multi-model fitting, thus preventing any interference with the association between other oral findings (dental caries) and negative impact on quality of life. 
Table 1. Distribution of the sample according to the severity of the impact on quality of life and associated factors.

\begin{tabular}{|c|c|c|c|}
\hline \multirow[b]{2}{*}{ Variable } & \multicolumn{3}{|c|}{ Impact on quality of life } \\
\hline & $\begin{array}{l}\text { Low } \\
\text { n (\%) }\end{array}$ & $\begin{array}{l}\text { High } \\
\mathrm{n}(\%)\end{array}$ & $\mathrm{p}$-value* \\
\hline \multicolumn{4}{|l|}{ Gender } \\
\hline Female & $340(51.1 \%)$ & $326(48.9 \%)$ & 0.134 \\
\hline Male & $298(55.4 \%)$ & $240(44.6 \%)$ & \\
\hline \multicolumn{4}{|c|}{ Cavitated carious lesions } \\
\hline No & $537(58.0 \%)$ & $389(42.0 \%)$ & $<0.001$ \\
\hline Yes & $101(36.3 \%)$ & 177 (63.7\%) & \\
\hline \multicolumn{4}{|l|}{ SVI } \\
\hline Low vulnerability & $415(54.7 \%)$ & $344(45.3 \%)$ & 0.126 \\
\hline High vulnerability & $223(50.1 \%)$ & $222(49.9 \%)$ & \\
\hline \multicolumn{4}{|l|}{ Type of school } \\
\hline Private & $181(64.0 \%)$ & 102 (36.0\%) & $<0.001$ \\
\hline Public & 457 (49.6\%) & $464(50.4 \%)$ & \\
\hline \multicolumn{4}{|l|}{ Caregivers' schooling } \\
\hline $\begin{array}{l}\geq 8 \text { years of } \\
\text { education }\end{array}$ & $479(57.0 \%)$ & $361(43.0 \%)$ & $<0.001$ \\
\hline $\begin{array}{l}<8 \text { years of } \\
\text { education }\end{array}$ & $158(43.9 \%)$ & $202(56.1 \%)$ & \\
\hline \multicolumn{4}{|l|}{ Household income } \\
\hline$\geq 2 \mathrm{BMW}$ & $371(61.2 \%)$ & $235(38.8 \%)$ & $<0.001$ \\
\hline$<2 \mathrm{BMW}$ & 257 (43.9\%) & $329(56.1 \%)$ & \\
\hline \multicolumn{4}{|c|}{ Residents in the household } \\
\hline$\leq 4$ & $403(55.7 \%)$ & $320(44.3 \%)$ & 0.011 \\
\hline$>4$ & $224(48.2 \%)$ & $241(51.8 \%)$ & \\
\hline
\end{tabular}

\section{Discussion}

Children's oral health can have an impact on their eating, smiling, speaking, and socializing. And when these activities are impaired, their quality of life is affected. Studies have shown that dental caries can influence children's quality of life. ${ }^{26,27}$

In the present study, which is representative of the city of Belo Horizonte, in southeastern Brazil, children with untreated dental caries experienced a $41 \%$ higher impact on OHRQoL than those without untreated dental caries. This finding had already been reported in another study with 112 children aged 8 to 10 years. ${ }^{14}$ Other studies with children from different age groups and non-representative samples have been carried out to assess the association between dental caries and the impact on OHRQoL. A study carried out with 6- and 7-year-old Brazilian children showed that children's quality of life was negatively influenced by untreated cavitated dentine lesions and their consequences. ${ }^{15}$ In addition, when dental caries is more severe, it has a negative impact on parents' quality of life. ${ }^{20}$ Among younger Brazilian children (aged 2-5 years), the prevalence of any impact on OHRQoL is almost three times higher for children with dental caries compared to those who are caries-free. ${ }^{28}$

Malocclusion was used as a confounding variable because anterior segment spacing, a common finding at this stage, is statistically associated with impact on children's OHRQoL. ${ }^{29}$ Furthermore, the prevalence of malocclusion $(32.2 \%)$ was higher than that of dental caries $(23.1 \%)$ in this sample. Moreover, the DAI was developed for permanent teeth and tends to be oversensitive during the mixed dentition period, possibly biasing the results due to transient developmental conditions. ${ }^{30}$

The prevalence rates of dental caries and malocclusion were smaller than the prevalence of high impact on OHRQoL (47.0\%). That is probably because the children experienced many problems during the mixed dentition period (ages 6 to 12 years) related to natural processes, such as exfoliation of deciduous teeth, dental eruption, space due to an unerupted permanent tooth, which eventually affected their quality of life. This finding was expected owing to the complexity of changes at this stage and to the lack of specific indices for this phase. Therefore, this study is of great relevance, since studies on children in the mixed dentition stage are rare.

No statistically significant differences were found between genders regarding the impact on OHRQoL unlike other studies on children from different age groups. ${ }^{3,11}$ There may be several reasons for that, including the fact that most of the children in this study were in the mixed dentition phase. The recently erupted anterior permanent teeth did not have enough time to exhibit signs of the disease and the anterior primary teeth most affected by early childhood caries and more related to facial appearance had already exfoliated. Perhaps, the result could be different if esthetic had been affected by dental caries in the anterior region of the mouth, as shown by other studies with older children. 
Table 2. Univariate and multivariate Poison regressions explaining the influence of independent variables on the high impact on OHRQoL.

\begin{tabular}{|c|c|c|c|c|}
\hline \multirow{2}{*}{ Independent variable } & \multicolumn{2}{|c|}{ Univariate Poison regression } & \multicolumn{2}{|c|}{ Multivariate Poison regression } \\
\hline & PR (95\%) & $p$-value & PR (95\%) & $\mathrm{p}$-value \\
\hline \multicolumn{5}{|l|}{ Gender } \\
\hline Female & $1.09(0.97-1.24)$ & 0.274 & & \\
\hline Male & 1 & & & \\
\hline \multicolumn{5}{|l|}{ Cavitated carious lesion } \\
\hline Yes & $1.52(1.35-1.70)$ & $<0.001$ & $1.41(1.25-1.59)$ & $<0.001$ \\
\hline No & 1 & & 1 & \\
\hline \multicolumn{5}{|l|}{ SVI } \\
\hline High & $1.10(0.97-1.24)$ & 0.267 & & \\
\hline Low & 1 & & & \\
\hline \multicolumn{5}{|l|}{ Residents in the household } \\
\hline$>4$ & $1.17(1.04-1.32)$ & 0.065 & & \\
\hline$\leq 4$ & 1 & & & \\
\hline \multicolumn{5}{|l|}{ Type of school } \\
\hline Public & $1.39(1.18-1.65)$ & 0.002 & & \\
\hline Private & 1 & & & \\
\hline \multicolumn{5}{|l|}{ Caregivers' schooling } \\
\hline$<8$ years of education & $1.30(1.16-1.47)$ & 0.003 & & \\
\hline$\geq 8$ years of education & 1 & & & \\
\hline \multicolumn{5}{|l|}{ Household income } \\
\hline$<2 \mathrm{BMW}$ & $1.45(1.28-1.64)$ & $<0.001$ & $1.31(1.15-1.51)$ & 0.001 \\
\hline$\geq 2 \mathrm{BMW}$ & 1 & & 1 & \\
\hline
\end{tabular}

Children whose household income was less than 2 BMW were $31 \%$ more likely to experience a high impact on OHRQoL than those whose household income was higher than 2 BMW. In other studies carried out in Brazil with 12-year-olds, household income showed a statistically significant association with all health domains of the $\mathrm{CPQ}_{11-14}$, the version of CPQ suitable for age of 12 years and showed a strong negative effect on OHRQoL. In younger Brazilian children (aged 2-5 years), lower household income was also significantly associated with OHRQoL, ${ }^{9}$ confirming that household income influences COHRQoL regardless of the child's age.

The prevalence of dental caries in the analyzed sample (23.1\%) is significantly lower than that found in the pilot study $(62.3 \%)$ conducted at a public school, indicating that dental caries experience and severity score of dental caries are influenced by the type of school. ${ }^{31}$ The present study assessed children from both public and private schools.

This study, which is representative of Belo Horizonte, southern Brazil, and innovates by including 8-10-year-olds, underscores the importance of public health policies targeted at the treatment of dental caries, a treatable disease, thus avoiding its impact on the quality of life of these children. Most economically underprivileged children had a higher prevalence of dental caries and the greatest impact of the disease on their quality of life. In addition, public resources should be used to prevent caries in the permanent dentition of children in this age group.

\section{Conclusion}

This study demonstrated that dental caries and lower family income cause a negative impact on OHRQoL. 


\section{References}

1. Nuttall NM, Steele JG, Evans D, Chadwick B, Morris AJ, Hill K. The reported impact of oral condition on children in the United Kingdom, 2003. Br Dent J. 2006;200(10):551-5. doi:10.1038/sj.bdj.4813586

2. Edelstein BL. The dental caries pandemic and disparities problem. BMC Oral Health. 2006;6(Suppl 1):S2. doi:10.1186/1472-6831-6-S1-S2

3. Moure-Leite FR, Ramos-Jorge J, Ramos-Jorge ML, Paiva SM, Vale MP, Pordeus IA. Impact of dental pain on daily living of five-year-old Brazilian preschool children: prevalence and associated factors. Eur Arch Paediatr Dent. 2011;12(6):293-7. doi:10.1007/BF03262826

4. Sheiham A. Dental caries affects body weight, growth and quality of life in pre-school children. Br Dent J. 2006;201(10):625-6. doi:10.1038/sj.bdj.4814259

5. Gaur S, Nayak R. Underweight in low socioeconomic status preschool children with severe early childhood caries. J Indian Soc Pedod Prev Dent. 2011;29(4):305-9. doi:10.4103/0970-4388.86375

6. Marques LS, Ramos-Jorge ML, Paiva SM, Pordeus IA. Malocclusion: esthetic impact and quality of life among Brazilian schoolchildren. Am J Orthod Dentofacial Orthop. 2006;129(3):424-7. doi:10.1016/j.ajodo.2005.11.003

7. Bianco A, Fortunato L, Nobile CG, Pavia M. Prevalence and determinants of oral impacts on daily performance: results from a survey among school children in Italy. Eur J Public Health. 2010;20(5):595-600. doi:10.1093/eurpub/ckp179

8. Gradella CM, Bernabé E, Bönecker M, Oliveira LB. Caries prevalence and severity, and quality of life in Brazilian 2to 4-year-old children. Community Dent Oral Epidemiol. 2011;39(6):498-504. doi:10.1111/j.1600-0528.2011.00625.x

9. Abanto J, Carvalho TS, Mendes FM, Wanderley MT, Bönecker M, Raggio DP. Impact of oral diseases and disorders on oral health-related quality of life of preschool children. Community Dent Oral Epidemiol. 2011;39(2):105-14. doi:10.1111/j.1600-0528.2010.00580.x

10. Bönecker M, Abanto J, Tello G, Oliveira LB. Impact of dental caries on preschool children's quality of life: an update. Braz Oral Res. 2012;26(spe 1):103-7. doi:10.1590/S1806-83242012000700015

11. Kumar S, Goyal A, Tadakamadla J, Tibdewal H, Duraiswamy P, Kulkarni S. Oral health related quality of life among children with parents and those with no parents. Community Dent Health. 2011;28(3):227-31.

12. Koposova N, Eriksen HM, Widstrãm E, Eisemann M, Opravin A, Koposov R. Oral health-related quality of life among 12-year-olds in Northern Norway and North-West Russia. Oral Health Dent Manag. 2012;11(4):206-14.

13. Krisdapong S, Prasertsom P, Rattanarangsima K, Sheiham A. Impacts on quality of life related to dental caries in a national representative sample of Thai 12- and 15-year-olds. Caries Res. 2013;47(1):9-17. doi:10.1159/000342893
14. Martins-Júnior PA, Oliveira M, Marques LS, Ramos-Jorge ML. Untreated dental caries: impact on quality of life of children of low socioeconomic status. Pediatr Dent. 2012;34(3):49-52.

15. Leal SC, Bronkhorst EM, Fan M, Frencken JE. Untreated cavitated dentine lesions: impact on children's quality of life. Caries Res. 2012;46(2):102-6. doi:10.1159/000336387

16. Barbosa TS, Tureli MC, Nobre-dos-Santos M, PuppinRontani RM, Gavião MB. The relationship between oral conditions, masticatory performance and oral health-related quality of life in children. Arch Oral Biol. 2013;58(9):1070-7. doi:10.1016/j.archoralbio.2013.01.012

17. Rebok G, Riley A, Forrest C, Starfield B, Green B, Robertson $\mathrm{J}$ et al. Elementary school-aged children's reports of their health: a cognitive interviewing study. Qual Life Res. 2001;10(1):59-70. doi:10.1023/A:1016693417166

18. Cohen-Carneiro F, Souza-Santos R, Rebelo MA. Quality of life related to oral health: contribution from social factors. Cien Saude Colet. 2011;16(Suppl 1):1007-15. doi:10.1590/S1413-81232011000700033

19. Piovesan C, Antunes JL, Guedes RS, Ardenghi TM. Impact of socioeconomic and clinical factors on child oral health-related quality of life (COHRQoL). Qual Life Res. 2010;19(9):1359-66. doi:10.1007/s11136-010-9692-7

20. Abanto J, Paiva SM, Raggio DP, Celiberti P, Aldrigui JM, Bönecker M. The impact of dental caries and trauma in children on family quality of life. Community Dent Oral Epidemiol. 2012;40(4):323-31. doi:10.1111/j.1600-0528.2012.00672.x

21. Kirkwood BR, Stern J. Essentials of medical statistics. 2nd ed. Malden: Blackwell Science; 2003. p. 413-28.

22. World Health Organization. Oral health surveys. Basic methods. 4th ed. Geneva: World Health Organization; 1997.

23. Cons NC, Jenny J, Kohout FJ. DAI: the Dental Aesthetic Index. Iowa: College of Dentistry, University of Iowa; 1986.

24. Nahas MI, Ribeiro C, Esteves O, Moscovitch S, Martins VL. O mapa da exclusão social de Belo Horizonte: metodologia de construção de um instrumento de gestão urbana. Cad Cienc Soc. 2000;7:75-88.

25. Martins MT, Ferreira FM, Oliveira AC, Paiva SM, Vale MP, Allison PJ et al. Preliminary validation of the Brazilian version of the Child Perceptions Questionnaire 8-10. Eur J Paediatr Dent. 2009;10(3):135-40.

26. Torres CS, Paiva SM, Vale MP, Pordeus IA, Ramos-Jorge ML, Oliveira AC et al. Psychometric properties of the Brazilian version of the Child Perceptions Questionnaire (CPQ11-14) - short forms. Health Qual Life Outcomes. 2009;7(7):43. doi:10.1186/1477-7525-7-43

27. Foster Page LA, Thomson WM. Caries prevalence, severity, and 3-year increment, and their impact upon New Zealand adolescents' oral-health-related quality of life. J Public Health Dent. 2012;72(4):287-94. doi:10.1111/j.1752-7325.2012.00336.x 
28. Kramer PF, Feldens CA, Ferreira SH, Bervian J, Rodrigues PH, Peres MA. Exploring the impact of oral diseases and disorders on quality of life of preschool children. Community Dent Oral Epidemiol. 2013 Aug;41(4):327-35. doi:10.1111/cdoe.12035

29. Sardenberg F, Martins MT, Bendo CB, Pordeus IA, Paiva SM, Auad SM et al. Malocclusion and oral health-related quality of life in Brazilian school children. Angle Orthod. 2013;83(1):83-9. doi:10.2319/010912-20.1
30. Keay PA, Freer TJ, Basford KE. Orthodontic treatment need and the dental aesthetic index. Aust Orthod J. 1993;13(1):4-7.

31. Martins MT, Sardenberg F, Abreu MH, Vale MP, Paiva SM, Pordeus IA. Factors associated with dental caries in Brazilian children: a multilevel approach. Community Dent Oral Epidemiol. 2014;42(4):289-99. doi:10.1111/cdoe.12087 